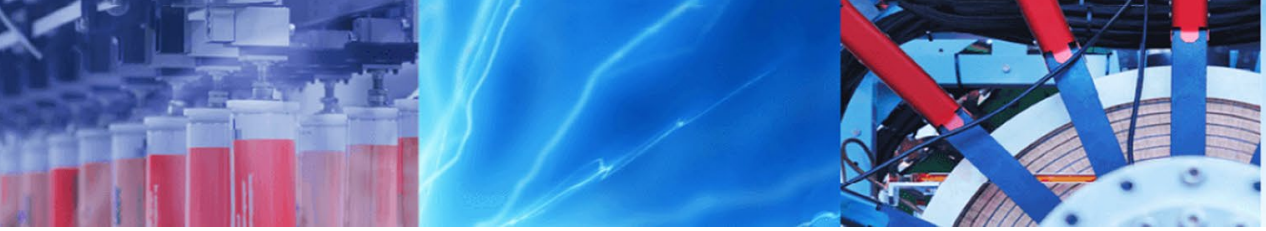

Research Article

\title{
Comparison of single-bed oxidative dehydrogenation of ethylbenzene with double-bed using $\mathrm{CO}_{2}$
}

\author{
Ebrahim Sadeghi ${ }^{1}$ [D $\cdot$ Maryam Saket Oskoui ${ }^{1} \cdot$ Masoumeh Khatamian $^{1}$
}

(c) Springer Nature Switzerland AG 2019

\begin{abstract}
The present study highlights the catalytic performance of $5 \mathrm{wt} \% \mathrm{Fe}_{2} \mathrm{O}_{3}$ supported on sodium chromosilicate (5F/NCS) in a single-bed reactor for dehydrogenation of ethylbenzene with $\mathrm{CO}_{2}$ and compares it with the catalytic performance of two subsequent catalysts (5F/NCS + industrial oxidation catalyst) in a double-bed reactor. The support of the target nanocomposite catalyst was obtained by hydrothermal treatment and subsequently was loaded with a medium amount of $5 \mathrm{wt} \% \mathrm{Y}^{-} \mathrm{Fe}_{2} \mathrm{O}_{3}$. Structural and textural characterizations of the catalysts were performed by means of X-ray diffraction, scanning electron microscopy, transmission electron microscopy, $\mathrm{N}_{2}$ physical adsorption analysis, and Fourier-transform infrared spectroscopy. The catalytic tests revealed that 5F/NCS in the single-bed reactor had a high ethylbenzene conversion (>54\%) and a low styrene selectivity (> 70\%). In comparison with this observation, in the double-bed reactor with the presence of oxidation catalysts, styrene selectivity increased significantly $(>91 \%)$, however; ethylbenzene conversion indicated a minor decrease ( $>50 \%)$. The high styrene selectivity $(>91 \%)$ and styrene yield $(>46 \%)$ in the double-bed reactor were ascribed to the coupling reaction of ethylbenzene dehydrogenation and RWGS as well as the synergistic effect of Pt-Sn in the structure of oxidation catalyst.
\end{abstract}

Keywords Oxidative dehydrogenation - Styrene - Oxidation catalyst - Pt-Sn bimetallic catalysts $\cdot \mathrm{CO}_{2}$ as a soft oxidant . Lattice oxygen · Cracking reactions

\section{Introduction}

Styrene (ST) is one of the platform chemicals for plastic and petrochemical industries, utilized primarily for the synthesis of polystyrene and ST copolymers such as acryIonitrile-butadiene-styrene (ABS), styrene acrylonitrile (SAN), styrene-butadiene rubber (SBR), fibers, ABA resin etc. [1-6]. At present, there are two main processes for the manufacture of ST. In the first one, ST is produced as a sideproduct in the epoxidation of propene with ethylbenzene (EB) hydroperoxide with Mo complex based catalysts. The second one and also the most important manufacturing route to $\mathrm{ST}$ is by the direct dehydrogenation of $\mathrm{EB}$ on iron oxide catalysts at $873-973 \mathrm{~K}$, just below the decomposition temperature of the reactant $[2,6-9]$. Because the reaction is highly endothermic and volume-increasing, a large amount of superheated steam is used to supply heat, decline the partial pressure of the reactants to shift the equilibrium to ST, and inhibit the buildup of coke or of coke precursors on catalyst surface to prolong the catalyst activity, and eventually keep the iron oxide in an appropriate oxidation state [8, 10-12]. However, the use of steam has a number of defects including waste of a large amount of latent heat of condensation during subsequent separation in the conventional process instead of being

Electronic supplementary material The online version of this article (https://doi.org/10.1007/s42452-019-0681-3) contains supplementary material, which is available to authorized users.

Ebrahim Sadeghi, ebrahim.sadegi@gmail.com | ${ }^{1}$ Physical Inorganic Chemistry Research Laboratory, Department of Inorganic Chemistry, Faculty of Chemistry, University of Tabriz, Tabriz, Iran.

SN Applied Sciences (2019) 1:658 | https://doi.org/10.1007/s42452-019-0681-3

Received: 3 February 2019 / Accepted: 28 May 2019 / Published online: 1 June 2019 
recovered, catalyst deactivation, and depletion of $E B$ and ST by steam reforming $[2,8,9,13-15]$.

To overcome the mentioned flaws in the commercial process with steam many efforts have been put forward to improve the process by making it steam-free and applying lower temperatures. Therefore, other oxidants have been examined in oxidative dehydrogenation $(\mathrm{ODH})$ of $\mathrm{EB}$ including dry air, $\mathrm{O}_{2}, \mathrm{CO}_{2}, \mathrm{~N}_{2} \mathrm{O}$, and $\mathrm{SO}_{2}[2,5,6,16]$. Dehydrogenation in the presence of $\mathrm{O}_{2}$, however, requires less energy, it leads to burning a significant amount of valuable hydrocarbon $[5,17] . \mathrm{N}_{2} \mathrm{O}$ and $\mathrm{SO}_{2}$ are hazardous gases and preferably they cannot be utilized in ODH of EB to prevent their pernicious effect on human and the environment [18]. On the contrary, $\mathrm{CO}_{2}$ as a greenhouse gas, can decrease the partial pressure of reactants more effectively than steam, has the highest heat capacity among various typical gases, reduce energy consumption, accelerate the reaction rate, suppress the catalyst deactivation, and alleviate thermodynamic equilibrium limitations $[1,5,6$, $9,14,19]$. Furthermore, it is widely believed that carbon dioxide works very well in EB dehydrogenation as the soft oxidant and diluent to improve both the conversion and selectivity. The order of catalytic activity and selectivity for ST according to carrier gas was $\mathrm{CO}_{2}>\mathrm{N}_{2}>\mathrm{H}_{2} \mathrm{O}$ [20]. Additionally, industrial use of $\mathrm{CO}_{2}$ is increasingly important in many aspects especially the greenness of the process where $\mathrm{CO}_{2}$ is consumed during the process [6]. As a consequence, $\mathrm{ODH}$ of ethylbenzene with $\mathrm{CO}_{2}$ as a soft oxidant has attracted a considerable attention $[5,13,17,19$, 21-24]. ODH of EB (3) in the presence of $\mathrm{CO}_{2}$ proceeds via two reactions [1, 2]: first $E B$ is dehydrogenated to $S T$ and $H_{2}$ (Eq. 1), subsequently $\mathrm{CO}_{2}$ employed in this reaction reacts with $\mathrm{H}_{2}$ produced in the $\mathrm{EB}$ dehydrogenation reaction to yield $\mathrm{CO}$ and $\mathrm{H}_{2} \mathrm{O}$ via RWGS (Eq. 2). Moreover, $\mathrm{CO}_{2}$ can act as coke gasifier according to (Eq. 4).

$$
\begin{aligned}
& \mathrm{C}_{6} \mathrm{H}_{5} \mathrm{CH}_{2}-\mathrm{CH}_{3} \leftrightarrow \mathrm{C}_{6} \mathrm{H}_{5} \mathrm{CH} \\
& \quad=\mathrm{CH}_{2}+\mathrm{H}_{2} \quad \Delta H_{298 K}=117.6 \mathrm{KJ} \mathrm{mol}^{-1} \\
& \mathrm{CO}_{2}+\mathrm{H}_{2} \leftrightarrow \mathrm{CO}+\mathrm{H}_{2} \mathrm{O} \quad \Delta \mathrm{H}_{298 K}=41.6 \mathrm{KJ} \mathrm{mol}^{-1} \\
& \mathrm{C}_{6} \mathrm{H}_{5} \mathrm{CH}_{2}-\mathrm{CH}_{3}+\mathrm{CO}_{2} \leftrightarrow \mathrm{C}_{6} \mathrm{H}_{5} \mathrm{CH} \\
& \quad=\mathrm{CH}_{2}+\mathrm{CO}+\mathrm{H}_{2} \mathrm{O} \quad \Delta H_{298 K}=159.2 \mathrm{KJ} \mathrm{mol}^{-1} \\
& \mathrm{C}+\mathrm{CO}_{2} \leftrightarrow 2 \mathrm{CO}
\end{aligned}
$$

In past years, extensive efforts have been made in order to develop new catalysts for $\mathrm{ODH}$ of $\mathrm{EB}$, since the commercial catalysts do not work effectively in such a coupling system. The efficient catalysts for $\mathrm{ODH}$ of EB are mainly supported metal oxides, including $\mathrm{Fe}-$, $\mathrm{Cr}-$-, $\mathrm{V}-$, Ce-based oxides [12, 25]. Among them, vanadia and chromia exhibited high catalytic activity for the dehydrogenation of $E B$ with $\mathrm{CO}_{2}[26,27]$. In fact, the advantages of chromium in this particular process outweigh its disadvantages [28]. Additionally, effective supports for this reaction are based on inorganic metal oxides, $\mathrm{MgO}, \mathrm{SiO}_{2}, \mathrm{CeO}_{2}-\mathrm{ZrO}_{2}$, $\mathrm{TiO}_{2}-\mathrm{ZrO}_{2}, \mathrm{MnO}_{2}-\mathrm{ZrO}_{2}, \mathrm{~V}_{2} \mathrm{O}_{5}-\mathrm{CeO}_{2}, \mathrm{SnO}_{2}-\mathrm{ZrO}_{2}, \mathrm{FeO}_{\mathrm{x}}-\mathrm{Al}_{2} \mathrm{O}_{3}$, $\mathrm{TiO}_{\mathrm{x}}-\mathrm{Al}_{2} \mathrm{O}_{3}$ and $\mathrm{CeO}_{2}-\mathrm{ZrO}_{2}$ as an acid-base bi-functional support as well as catalyst [1, 9, 10, 12, 29]. Moreover, various zeolites as well as a wide range of carbonaceous materials, have been applied as the supports [11]. Based on the previous experiments [10], alkaline metals ( $\mathrm{Li}, \mathrm{Na}$ and $\mathrm{K}$ ), alkali earth metals ( $\mathrm{Ca}$ and $\mathrm{Mg}$ ) and other elements ( $\mathrm{Sb}$ and $\mathrm{Cr}$ ) were introduced as the promising promoters

Previously, we have reported ZSM-5 type chromosilicates [30], and chromosilicate-based composites [31] as effective catalysts for ODH of EB in the presence of $\mathrm{CO}_{2}$ and examined their performance (based on conversion and selectivity), stability (long-term use of catalysts up to three cycles without regeneration), and reusability. Also, previous study based on FTIR spectrum and TGA of the spent synthesized catalysts as well as SEM of the used industrial catalysts exhibited that the main culprit for the deactivation of dehydrogenation catalysts is partial reduction of $\mathrm{Fe}^{3+}$ ions (particularly reduction of the Fe-based catalysts to the magnetite-type [32]) in their structures [31]. It should be highlighted that based upon the mass loss of the spent catalyst after combustion from $300^{\circ} \mathrm{C}$ up to $550^{\circ} \mathrm{C}$, during the TGA experiment, the amount of coke deposition for the spent catalyst was calculated to be 2.75 $w t \%$ of the total weight of the catalyst [31]. As maintained by the mentioned facts, authors decided to select one of the catalysts ( $5 \mathrm{~F} / \mathrm{NCS}$ ( $5 \mathrm{wt} \% \mathrm{Fe}_{2} \mathrm{O}_{3}$ supported on sodium chromosilicate)) that had the lowest activity (the lowest ST selectivity amidst the composite catalysts-in a single-bed ODH reactor $-70.86 \%$ [31]) in this process and attempted to improve its performance. As a consequence, the foremost objective of the present contribution is to compare catalytic activity of 5F/NCS in a single-bed ODH reactor with a double-bed reactor having two catalysts including $5 F / N C S$ and industrial oxidation catalysts and discuss the primary reasons to enhance the catalytic activity. As the authors had previously conducted tests by a single-bed reactor, the double-bed reactor with an oxidation catalyst was a great choice; as oxidation catalysts would reinforce catalytic performance by eliminating hydrogen from the reaction environment-leading to higher ST selectivity. 


\section{Experimental section}

\subsection{Catalyst preparation}

\subsubsection{Preparing $\mathrm{Na}[\mathrm{Cr}] \mathrm{ZSM}-5$ (NCS) as the support}

As described in details previously [33], sodium chromosilicate was prepared by the hydrothermal procedure. In brief, first silicic acid and sodium carbonate were dissolved in distilled water and added slowly to the solution of $\mathrm{Cr}\left(\mathrm{NO}_{3}\right)_{3}-9 \mathrm{H}_{2} \mathrm{O}$ and sulfuric acid in water until $\mathrm{pH}$ of the solution was adjusted at 0.5 . Further, $\mathrm{pH}$ of the mixture was modified at 9 using concentrated sulfuric acid. Afterward, TPABr was added; and the obtained gel was stirred continuously at room temperature for about $4 \mathrm{~h}$. The crystallization of the prepared gel was made by hydrothermal treatment at $155^{\circ} \mathrm{C}$ for $100 \mathrm{~h}$. After crystallization, the synthesized samples were washed several times with distilled water and dried overnight in an oven at $120^{\circ} \mathrm{C}$. Finally, calcination was carried out for $5 \mathrm{~h}$ at $550^{\circ} \mathrm{C}$. In this contribution, sodium chromosilicate was washed with a large amount of distilled water to remove amorphous grains from pores. Thus, $\mathrm{NCS}_{\mathrm{BW}}$ and $\mathrm{NC}_{\mathrm{AW}}$ are referred to as sodium chromosilicate before washing and after washing with distilled water, respectively.

\subsubsection{Preparing ${ }-\mathrm{Fe}_{2} \mathrm{O}_{3}$}

Synthesis of $\mathrm{Y}-\mathrm{Fe}_{2} \mathrm{O}_{3}$ was started by adding in a drop wise manner of a $\mathrm{NaOH}$ solution (2.5 M) to an aqueous solution of iron (II) sulfate until the $\mathrm{pH}$ of the mixture was adjusted to 11 . The reactants were maintained under constant stirring for $6 \mathrm{~h}$, and the obtained solution (which was located in a heated water bath) split into a two-phase solution. The solid phase was afterward, centrifuged and washed with distilled water several times, dried at room temperature and calcination at $200{ }^{\circ} \mathrm{C}$ under air flow for $45 \mathrm{~min}$.

\subsubsection{Synthesis of $\mathrm{Fe}_{2} \mathrm{O}_{3} / \mathrm{Na}[\mathrm{Cr}] \mathrm{ZSM}-5$ (5F/NCS)}

In order to maintain the phase and nature of $\mathrm{Fe}_{2} \mathrm{O}_{3}$ as well as to have an insightful comparison between pure iron oxide and composite, $5 \mathrm{~F} / \mathrm{NCS}$ was prepared via solid state dispersion (SSD) method [34]. $5 \mathrm{wt} \%$ of iron oxide $\left(\gamma-\mathrm{Fe}_{2} \mathrm{O}_{3}\right)$ nanoparticles were mixed with a required amount of NCS in the presence of ethanol under vigorous stirring at room temperature until ethanol was evaporated during mixing. More importantly, to improve the interactions between precursors in mixed oxide catalysts, it is pivotal that precursors have an intimate contact with the least phase
Table 1 Chemical and physical properties of oxidation catalyst [TPC-R\&D]

\begin{tabular}{llll}
\hline $\begin{array}{l}\text { Chemical properties of } \\
\text { oxidation catalyst }\end{array}$ & $\begin{array}{l}\text { Physical properties of oxidation } \\
\text { catalyst }\end{array}$ \\
\hline $\mathrm{Pt}$ & Max $0.20 \mathrm{wt} \%$ & Particle size & $3 \mathrm{~mm}$ extrusions \\
$\mathrm{Sn}$ & Max $0.33 \mathrm{wt} \%$ & Side crush strength & $>2 \mathrm{MPa}$ \\
$\mathrm{Li}$ & Max 0.14 wt $\%$ & Surface area & $10 \mathrm{~m}^{2} / \mathrm{g}$ \\
$\mathrm{Fe}$ & $0.08 \mathrm{wt} \%$ & Pore volume & $0.29 \mathrm{ml} / \mathrm{g}$ \\
$\mathrm{Ca}$ & $0.01 \mathrm{wt} \%$ & & \\
$\mathrm{Cl}$ & $<0.10 \mathrm{wt} \%$ & & \\
\hline
\end{tabular}

segregation. All of which can be achieved by solid state preparation method [35].

\subsubsection{Oxidation catalyst}

Industrial oxidation catalyst (OC) was obtained from Tabriz Petrochemical Company-Research \& Develop (TPC-R\&D). There are a number of pretreatment processes for oxidation catalysts [36, 37]; however, the authors utilized OC without further purification. The chemical and physical properties of oxidation catalyst are given in Table 1.

\subsection{Apparatus and procedure}

Catalytic reaction of dehydrogenation of EB using $\mathrm{CO}_{2}$ was carried out in a fixed bed quartz reactor. The singlebed reactor for ODH of EB contained only $2 \mathrm{~g}$ of $5 \mathrm{~F} / \mathrm{NCS}$ loaded between quartz beds and double-bed reactor for dehydrogenation and oxidation consisted of $2 \mathrm{~g}$ of $5 \mathrm{~F} / \mathrm{NCS}$ followed by $2 \mathrm{~g}$ of oxidation catalyst supported by quartz beds (see Scheme 1). The reaction conditions were the same for both catalytic reactions. The reaction was performed at $873 \mathrm{~K}$ and atmospheric pressure for $4 \mathrm{~h}$. Before the start of the reaction, the catalyst was treated with the $\mathrm{N}_{2}$ flow $\left(100 \mathrm{~mL} \cdot \mathrm{min}^{-1}\right)$ from room temperature to $873 \mathrm{~K}$ at a heating rate of $145 \mathrm{~K} / \mathrm{h}$ and kept at this temperature for 30 min then $\mathrm{N}_{2}$ was replaced with $\mathrm{CO}_{2}$ gas $(36.64 \mathrm{~mL}$. $\left.\mathrm{min}^{-1}\right)$. EB was fed into the reactor at a constant rate (32.64 mmol. $\mathrm{h}^{-1}$ ) by means of a syringe pump. The outlet vapor was condensed in a cold trap of an ice bath and analyzed by a Varian 3800 CX gas chromatograph apparatus using aflame inductivity detector (FID). EB conversion and ST selectivity are calculated as per the following (Eq. 5) and (Eq. 6), respectively:

$\mathrm{EB}$ conversion $=\frac{E B_{\text {in }}-E B_{\text {out }}}{E B_{\text {in }}}$

ST selectivity $=\frac{S T_{\text {out }}}{E B_{\text {in }}-E B_{\text {out }}}$ 


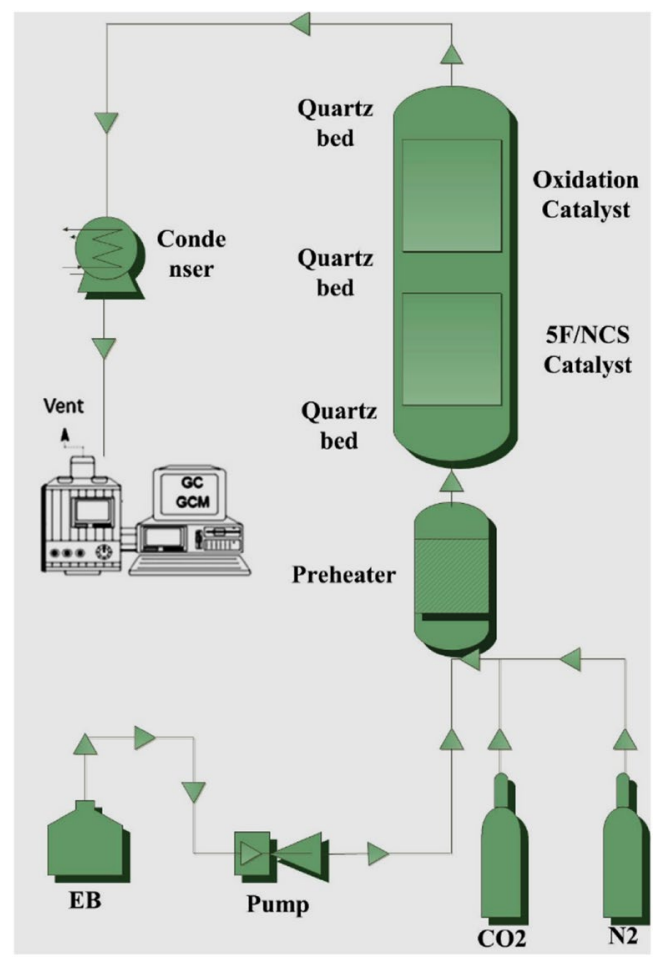

Scheme 1 Simplified schematic diagram of the double-bed reactor for dehydrogenation and oxidation of $\operatorname{EB}[30,31]$

where, $\mathrm{EB}_{\text {in }}$ is the amount of $\mathrm{EB}$ at the inlet and $\mathrm{EB}_{\text {out }}$ and $\mathrm{ST}_{\text {out }}$ are the amounts of EB and ST present in the product mixture respectively.

\subsection{Characterization of catalysts}

$\mathrm{X}$-ray powder diffraction (XRD) patterns were recorded in an STOE X-ray diffractometer (Version PKS-2.01). The Cu Ka radiation $(\lambda=1.540598 \AA$ ) $)$ was used and diffractograms were collected with a $2 \theta$ step of 0.06 and a counting time of $1 \mathrm{~s}$ per step. Diffraction peaks recorded between $4^{\circ}$ and $70^{\circ}$ have been used to identify the structure obtained at $40 \mathrm{kV}$ and $30 \mathrm{~mA}$. Scanning electron microscopy (SEM) pictures were determined on a Philips XL-30 system equipped with an EDX detector on the samples coated previously with a thin layer of gold. Nitrogen adsorption and desorption isotherms were measured at $77 \mathrm{~K}$ on a BELSORP mini, BEL Japan Inc. The specific surface area was calculated using the Brunauer-Emmett-Teller (BET) model. The pore size distributions were obtained from the desorption branch of the nitrogen isotherms by the Barrett-Joyner-Halenda (BJH) method. Transmission electron microscopy (TEM) images were recorded on a $208 \mathrm{~S}$ PHILIPS microscope operated at $100 \mathrm{~kW}$. Fourier transform infrared spectroscopy (FTIR) measurements were performed using a spectrophotometer (Tensor 27) over the wavenumber $4000-400 \mathrm{~cm}^{-1}$.

\section{Result and discussion}

\subsection{Morphology studies}

SEM images of the NCS sample after and also before washing with water are shown in Fig. 1c,d respectively. It can be distinguished that NCS appears as well-structured coffin-type crystals possessing relatively large sizes (about 20-21 $\mu \mathrm{m}$ ). According to these SEM images of NCS samples, it seems that the growth of crystal grains occurred well. In spite of the formation of well-structured crystals, some amorphous grains can be detected, which could be as a result of incomplete crystallization of some particles or may be attributed to $\mathrm{CrO}_{3}$ particles. In this work, the NCS sample was used as a support after washing it with
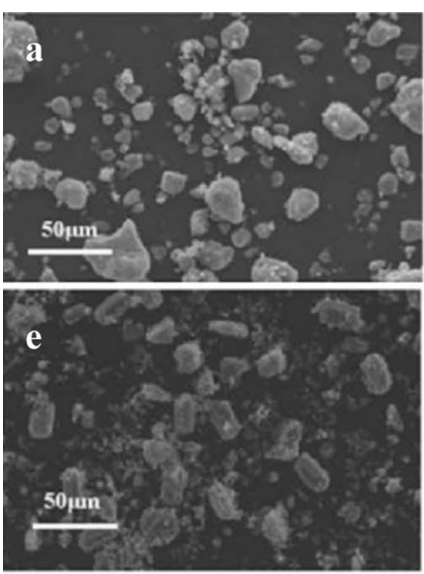
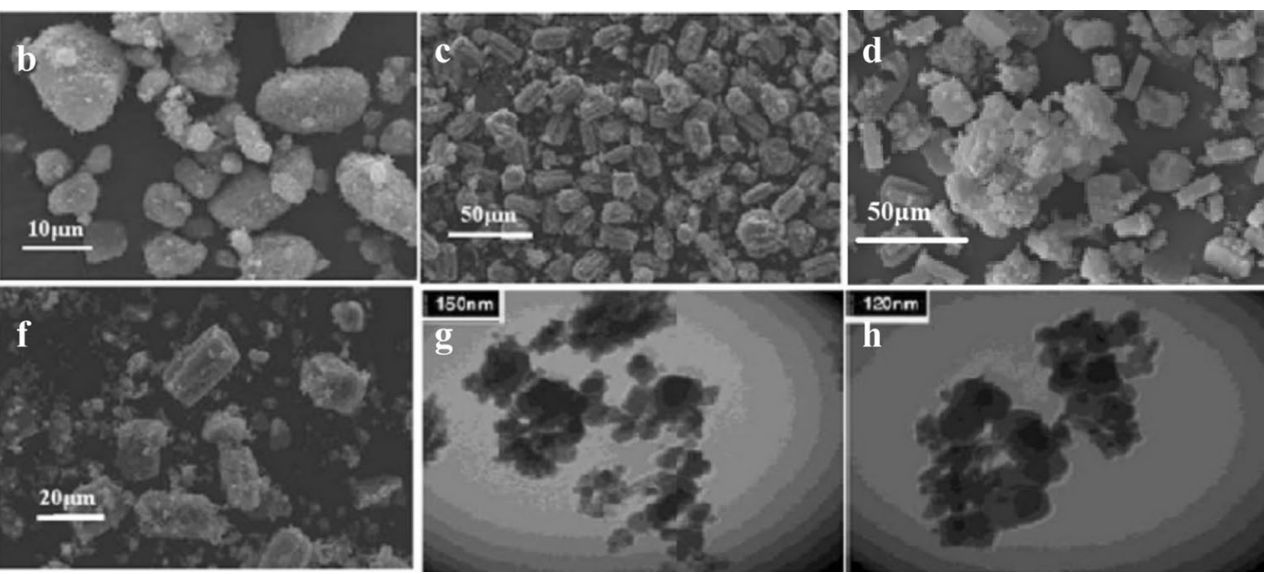

Fig. 1 SEM images of $\mathbf{a}, \mathbf{b} \mathrm{Fe}_{2} \mathrm{O}_{3}, \mathbf{c ~ N C S}$ after washing, $\mathbf{d}$ NCS before washing, and $\mathbf{e}, \mathbf{f}$ 5F/NCS samples. TEM images of $\mathbf{g}$, $\mathbf{h}$ 5F/NCS composite 
Fig. 2 XRD patterns of the prepared samples; (a) $\mathrm{Y}-\mathrm{Fe}_{2} \mathrm{O}_{3}$, (b) $\mathrm{NCS}_{\mathrm{BW}}$ (c) $\mathrm{NCS}_{\mathrm{AW}}$ (d) $5 \mathrm{~F} / \mathrm{NCS}$

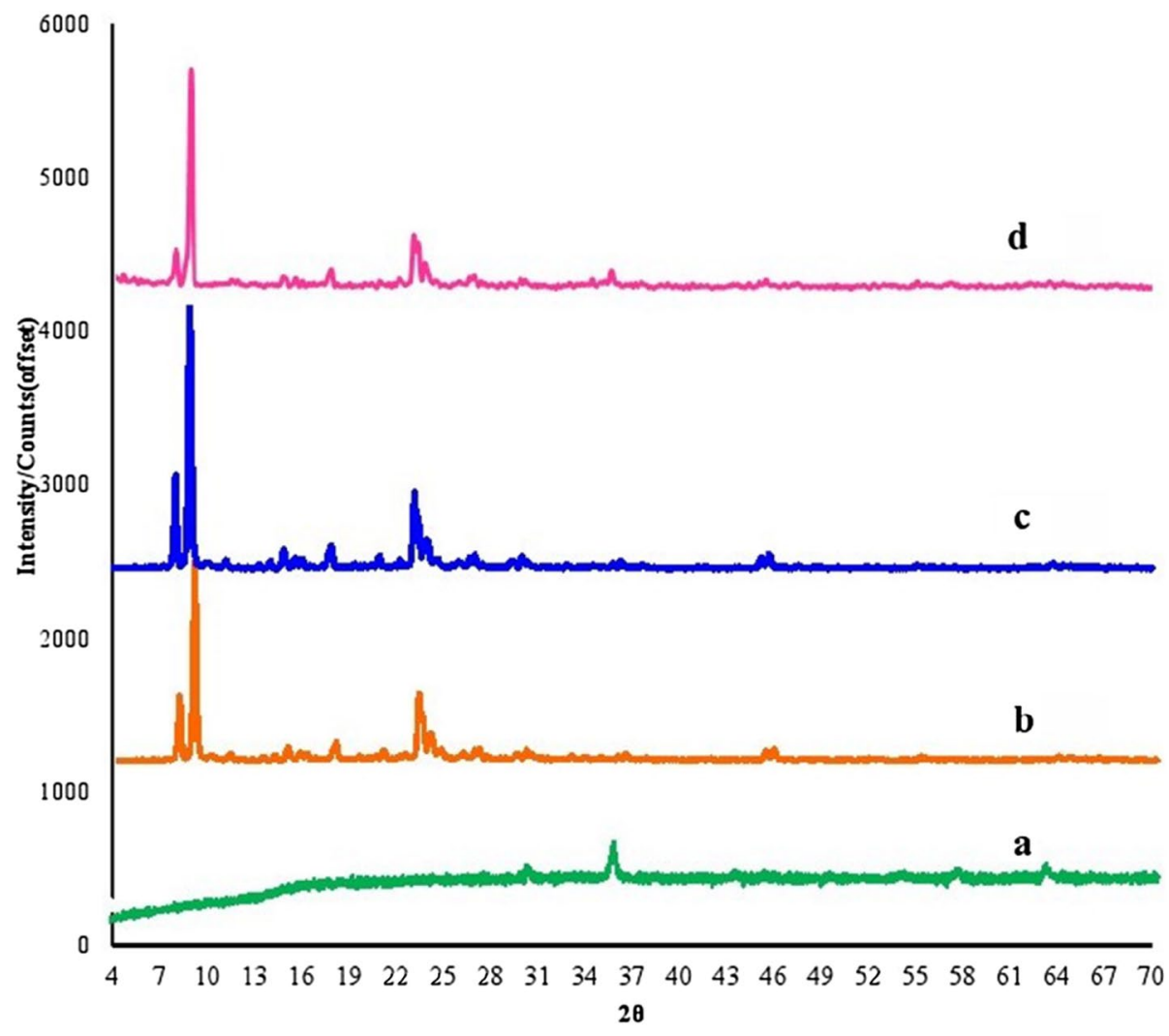

a large amount of water for the purpose of removing the extra amorphous grains as much as possible. As mentioned in our previous work [31] after washing this sample with a large amount of water, it is possible to recognize the nature of the mentioned amorphous particles by performing SEM analysis. As it can be observed in Fig. 1c, a great deal of these particles can be removed which could be attributed to $\mathrm{CrO}_{3}$ particles and the remaining particles which have no specific shapes can be related to amorphous grains of NCS sample. On the other hand, after loading of the $\mathrm{Fe}_{2} \mathrm{O}_{3}$ nanoparticles into the structure of the NCS sample (as the support) for preparation of the desired composite ( $5 \mathrm{~F} / \mathrm{NCS}$ ) with $5 \% \mathrm{Fe}_{2} \mathrm{O}_{3}$ (Fig. 1e, f), due to the interference of $\mathrm{Fe}_{2} \mathrm{O}_{3}$ nanoparticles, the mentioned extra grains on the NCS crystals increased. Regarding the fact that the SEM image of the $\mathrm{Fe}_{2} \mathrm{O}_{3}$ nanoparticles has as similar appearance (Fig. 1a, b) as the amorphous grains, this result can be expectable. Indeed, the TEM image of 5F/ NCS sample (Fig. 1g, h) illustrates the highly concentrated agglomeration of the particles, with diameter around 10-20 nm.

It should be highlighted that conventional catalysts preparation methods such as impregnation, co-precipitation and sol-gel which are operated in aqueous environment, the intimate contact of precursors can hardly be controlled due to the inherent different solubility products and complex influencing factors ( $\mathrm{pH}$, concentration, temperature, aging time, drying mode). On the other hand, solid state method enjoys advantages like simple operation, easy control of parameters and friendly to environment. Apart from the mentioned benefits of solid state process, large surface area and high porosity are very likely in case of catalysts prepared by this method [35].

\subsection{XRD analysis}

The XRD patterns of the obtained samples are illustrated in Fig. 2. For the purpose of comparison, Fig. 2 also contains the patterns of unsupported $\mathrm{Fe}_{2} \mathrm{O}_{3}$ and pure sodium chromosilicate (NCS) after and before washing with distilled water.

As can be seen in this image, XRD patterns of the prepared $\mathrm{Na}[\mathrm{Cr}] \mathrm{ZSM}-5$ (NCS) confirms the formation of ZSM-5 zeolite structure with orthorhombic symmetry according to the literature [38], which can be detected by peaks at $2 \theta=7.94,8.86,23.10,23.9$, and 24.45 illustrating (011), (200), (051), (033), and (313) planes of crystal structure, respectively. After loading the desired amount of $\mathrm{Y}^{-}-\mathrm{Fe}_{2} \mathrm{O}_{3}$, (5 wt\%) for preparation of 5F/NCS composite, the main diffraction peak related to $\mathrm{Fe}_{2} \mathrm{O}_{3}$ can be detected at $2 \theta=33.7$ (see Fig. 2). Furthermore, the 5F/NCS characteristic peaks of sodium chromosilicate (NCS) as the support in the XRD pattern of the composite can be seen with a slightly lower 

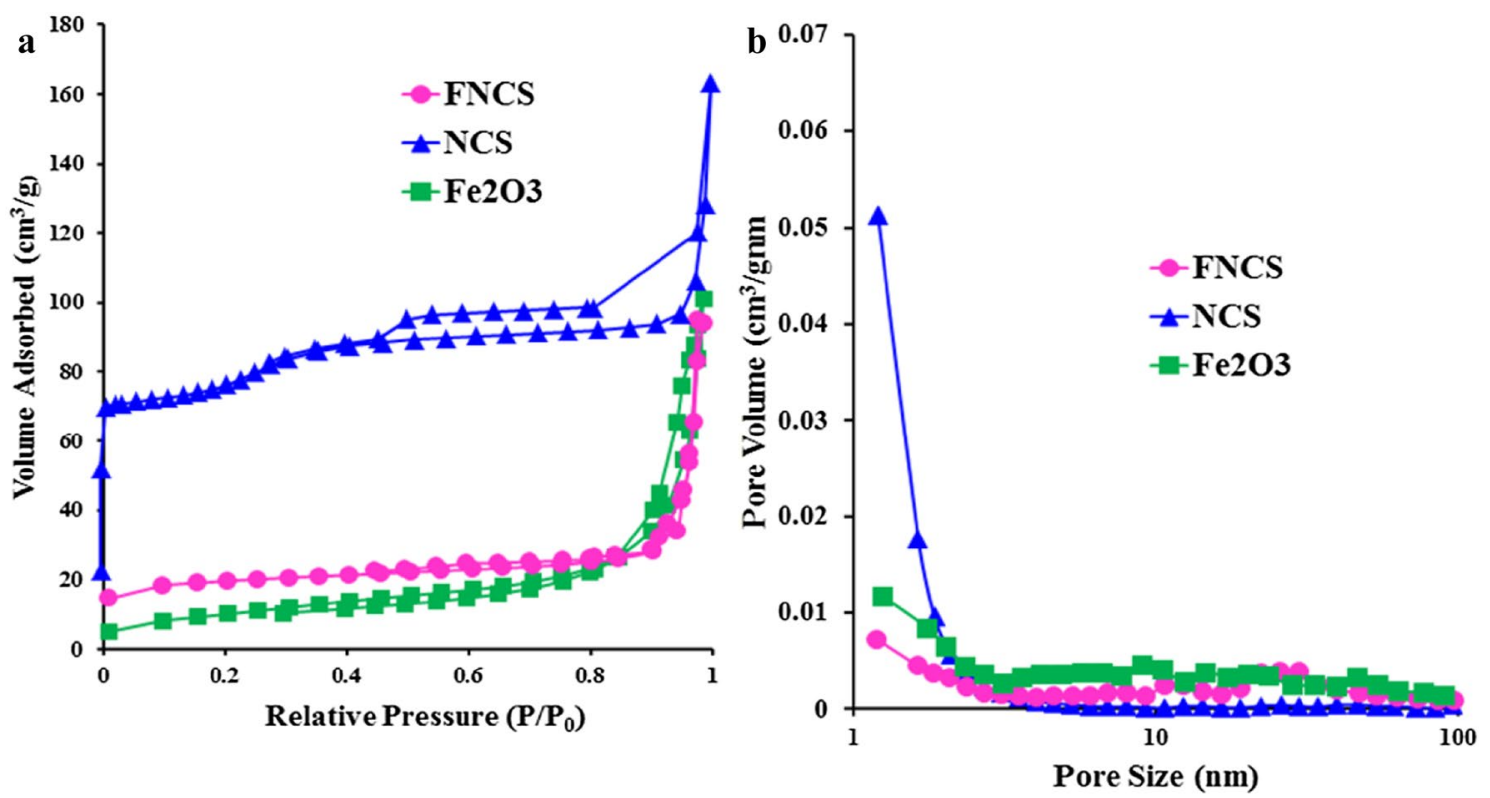

Fig. 3 a Nitrogen sorption isotherms of samples, $\mathbf{b}$ pore size distribution curves of samples

Table 2 Specific textural properties and catalytic activity of the prepared catalysts in EB dehydrogenation and oxidation at $873 \mathrm{~K}$ and $\mathrm{CO}_{2}$ flow of $36.64 \mathrm{~mL} \mathrm{~min} \mathrm{~m}^{-1}$ [31]

\begin{tabular}{|c|c|c|c|c|c|c|c|c|}
\hline Components & $\begin{array}{l}\text { BET surface } \\
\text { area }\left(\mathrm{m}^{2} \mathrm{~g}^{-1}\right)\end{array}$ & $\begin{array}{l}\text { Average pore } \\
\text { diameter }(\mathrm{nm})\end{array}$ & $\begin{array}{l}\text { Total pore } \\
\text { volume }\left(\mathrm{cm}^{3}\right. \\
\left.\mathrm{g}^{-1}\right)\end{array}$ & $X(\%)$ & $\mathrm{Bz}(\%)$ & Tol (\%) & S (\%) & $\begin{array}{l}\text { EB con- } \\
\text { version } \\
(\%)\end{array}$ \\
\hline $5 F / N C S$ & 61.12 & 8.036 & 0.1228 & 38.63 & 10.43 & 5.60 & 70.68 & 54.66 \\
\hline $5 \mathrm{~F} / \mathrm{NCS}+\mathrm{OC}$ & & & & 46.09 & 2.32 & 1.16 & 91.87 & 50.17 \\
\hline $\mathrm{NCS}_{\mathrm{AW}}$ & 316.62 & & & 44.81 & 2.24 & 3.32 & 88.96 & 50.37 \\
\hline $\mathrm{NCS}_{\mathrm{BW}}$ & 307.74 & 2.2620 & 0.1740 & 46.38 & 1.24 & 1.87 & 93.72 & 49.49 \\
\hline $\mathrm{Fe}_{2} \mathrm{O}_{3}$ & 36.10 & 17.31 & & 46.85 & 12.29 & 3.67 & 74.59 & 62.81 \\
\hline
\end{tabular}

$X$ styrene yield, $B z$ benzene, Tol toluene, $S$ styrene selectivity, $E B$ ethylbenzene intensity compared to that of the pure sodium chromosilicate confirming the formation of the composite.

\subsection{Nitrogen adsorption isotherms and pore size distribution}

For evaluation of the specific textural properties of the samples Brunauer-Emmett-Teller (BET) analysis was performed and thereby porous structure of the samples and their pore size distribution were investigated [39]. The adsorption-desorption isotherms and relating $(\mathrm{BJH})$ pore size distribution curves of all samples are shown in Fig. $3 a$, b respectively, and the textural properties are presented in Table 2. ${ }^{1}$ As can be distinguished in Fig. 3, and

\footnotetext{
1 All of the BET data which has been gathered in the Table 2 was reported by the operator of the analysis. For some of the samples, average pore diameter was not reported.
}

in accordance with IUPAC Classification of Gas Adsorption Isotherms, all of the samples reveal a type IV isotherm possessing a distinct step confirming the presence of mesoporosity [40]. The steep increment of adsorption step at low relative pressure $\left(\mathrm{P} / \mathrm{P}_{0}<0.1\right)$ (except for $\mathrm{Fe}_{2} \mathrm{O}_{3}$ nanoparti(le), is due to the presence of micropores in these samples. At medium amounts of $\mathrm{P} / \mathrm{P}_{0}$, a capillary condensation step and an $\mathrm{H} 3$-type hysteresis loop were detected, indicating the appearance of slit-like pores in the structure as a consequence of the loose gathering of plate-like particles [41].

$\mathrm{N}_{2}$ adsorption and desorption experiments on NCS sample lead to a step-wise desorption isotherm, indicating bimodal porosity, in spite of the fact that the adsorption branch exhibits only one step in which the size of both the open and blocked mesopores are illustrated (Fig. 3). It is noteworthy that the step-wise desorption isotherm exists as the encapsulated mesopores can empty at a lower pressure compared to the similar open pores [42]. 


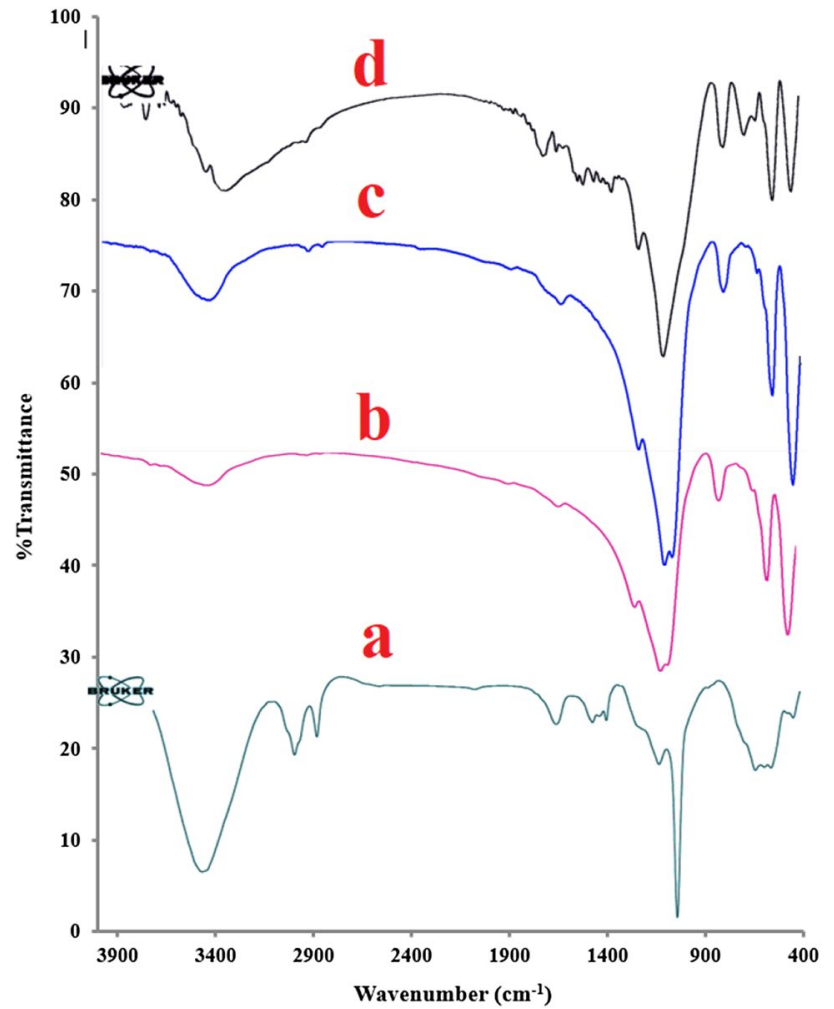

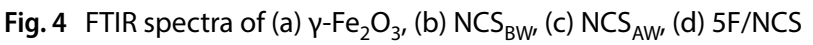

The pore size distribution was provided by using the Barret-Joyner-Halenda method via BJH analysis of adsorption isotherm data and presented in Fig. $3 \mathrm{~b}$.

\subsection{FTIR analysis}

FTIR spectra of the obtained samples are presented in Fig. 4. For the purpose of comparison, Fig. 4 also contains the spectra of unsupported $\mathrm{Fe}_{2} \mathrm{O}_{3}$ and pure sodium chromosilicate (NCS) after and before washing with distilled water. The spectra of chromosilicate-containing samples have the great similarity with the spectrum of ZSM-5 including the presence of zeolite-like building units e.g. the characteristic band of the pentasil structure (double ring vibration) possessing five-membered ring at around $549 \mathrm{~cm}^{-1}$ and bending vibration of T-O-T bend at about $445 \mathrm{~cm}^{-1}$ which are clearly detectable in the spectra of NCS-based samples. Furthermore, asymmetric stretching vibration of the T-O bond at around $1237 \mathrm{~cm}^{-1}$ for NCS sample can be related to external linkages between TO4 tetrahedrals. Moreover, the presence of the peaks at 449 and $638 \mathrm{~cm}^{-1}$ for nanoparticles of $\mathrm{Fe}_{2} \mathrm{O}_{3}$ and also its composite with NCS (5F/NCS) are attributed to the stretching vibrations of $\mathrm{Fe}-\mathrm{O}$ bond.

\subsection{Catalytic performance of the prepared samples}

Vapor phase dehydrogenation of $\mathrm{EB}$ with $\mathrm{CO}_{2}$ was carried out at $873 \mathrm{~K}$ and $1 \mathrm{~atm}$ over 5F/NCS catalyst in a singlebed reactor, and its results were reported in our previous study [31]. Herein, we report the dehydrogenation followed by oxidation of EB in a double-bed reactor with the same conditions. For a better comparison between two catalytic tests, the results have been brought together in Table 2. As it is obviously seen, ST yield and selectivity in the double-bed reactor have been improved significantly from 38.63 to 46.09 and 70.68 to 91.87 , respectively. However, EB conversion has a minor decrease in double-bed reactor compared to single-bed.

Synthesized 5F/NCS catalysts in both reactors loaded with $5 \mathrm{wt} \%$ of iron oxide exhibited a remarkable conversion of EB. In case of ODH to obtain ST by using iron-based catalysts, owing to $\mathrm{Fe}^{3+}$ ions as active but not necessarily selective components, high EB conversion was generally expected. Moreover, it has been discovered that oxygen deficiency of iron oxide in the supported catalyst is one of the most important factors in promoting the catalytic activity in the presence of $\mathrm{CO}_{2}$. Oxygen deficient sites of the supported iron oxide catalyst (such as NCS supported $\mathrm{Y}-\mathrm{Fe}_{2} \mathrm{O}_{3}$ ) seem to produce $\mathrm{CO}$ efficiently from the $\mathrm{CO}_{2}$ dissociation, and the adsorbed oxygen on the catalyst surface can also play a role on hydrogen abstraction from EB $[20,43]$ leading to high conversions for both cases. During dehydrogenation of $E B$ in the absence of an oxidant, the lattice oxygen of the catalyst takes part in $\mathrm{H}_{2}$ abstraction to form water. After the complete consumption of lattice oxygen of the catalyst surface, the rate of water generation declines with a gradual increase in the generation of molecular $\mathrm{H}_{2}$ [44]. On the other hand, by the introduction of $\mathrm{CO}_{2}$ as a mild oxidant that constantly supplies lattice oxygen and therefore avoids $\mathrm{H}_{2}$ formation $[45,46]$.

As mentioned previously, $\mathrm{CO}_{2}$ is more attractive compared to other oxidants such as $\mathrm{O}_{2}, \mathrm{NO}_{2}$ and $\mathrm{SO}_{2}$ because of being widespread, less harmful, low cost and mild oxidizing features $[47,48]$. In addition, from studies performed on $\mathrm{ODH}$ processes with $\mathrm{CO}_{2}$ we learned the oxygen vacancies in bulk catalysts could abstract the oxygen from $\mathrm{CO}_{2}$ molecules, forming dissociated oxygen and $\mathrm{CO}$. The formed oxygen vacancy could be re-oxidized by $\mathrm{CO}_{2}$, and the catalyst returned to its original state [49]. As reported, heteroatom doping was an effective method for improving the lattice oxygen content and oxygen mobility of transition metal oxide catalysts. Hence, doping iron, vanadium and chromium on the $\mathrm{Fe}_{2} \mathrm{O}_{3} / \mathrm{Y}-\mathrm{Al}_{2} \mathrm{O}_{3}$ leads to higher oxygen mobility and thereafter higher catalytic activity [47]. Watanabea et al. investigated the effect of the reduced state of the $\mathrm{BaZrO}_{3}(\mathrm{BZO})$ catalyst by electron-spin resonance (ESR) spectra and the effect of prereduction by 

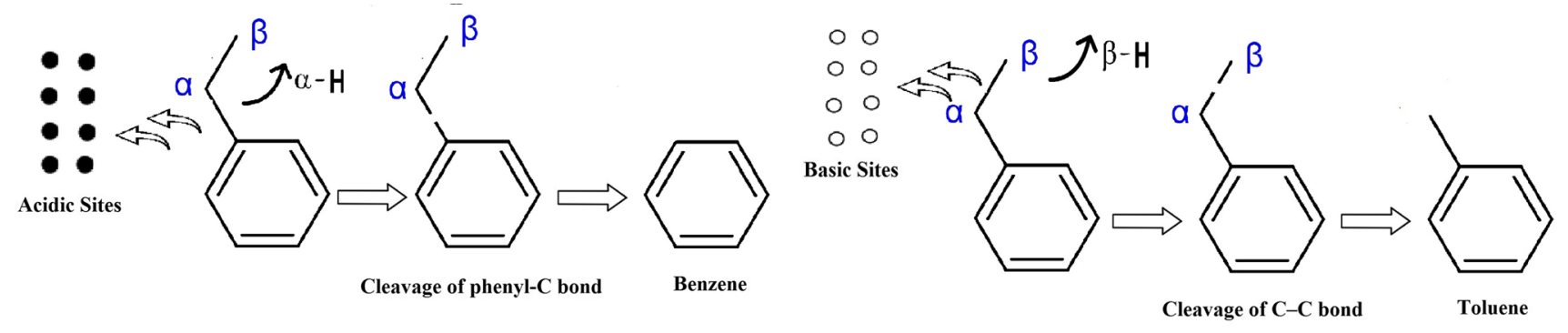

Scheme 2 Reaction schemes for the production of side-products of EB dehydrogenation reaction (benzene and toluene)

$\mathrm{H}_{2}$. Their efforts culminated by two following Eqs. (7) and (8) [32].

$$
\begin{aligned}
& \mathrm{H}_{2}+\mathrm{O}_{\text {lat }}^{2-} \rightarrow \mathrm{H}_{2} \mathrm{O}+\mathrm{V}_{\mathrm{ox}}+2 \mathrm{e}^{-} \\
& \mathrm{O}_{2}+\mathrm{V}_{\mathrm{ox}}+4 \mathrm{e}^{-} \rightarrow 2 \mathrm{O}_{\text {lat }}^{2-}
\end{aligned}
$$

Where $\mathrm{O}_{\text {lat }}^{2-}$ and $\mathrm{V}_{\text {ox }}$ denote a lattice oxygen and an oxygen vacancy in the catalyst, respectively. Based on the mentioned reactions, the formed oxygen vacancy could be reoxidized by $\mathrm{CO}_{2}$, and the catalyst returned to its original state. According to these explanations, presence of iron oxides in case $5 \mathrm{~F} / \mathrm{NCS}+\mathrm{OC}$ leads to the increasing defectsite concentration, and the defect-site is the active site for the $\mathrm{EB}$ dehydrogenation over $\mathrm{Fe}_{2} \mathrm{O}_{3}$ [32]. This fact clearly explains the difference between catalytic performance of $5 \mathrm{~F} / \mathrm{NCS}+\mathrm{OC}$ and $\mathrm{NCS}_{\mathrm{AW}}$ which they have nearly same conversion but the former catalyst is more active (refer to Table 2).

As it was previously mentioned in the introduction section, according to reaction (Eq. 1), dehydrogenation of EB produces $\mathrm{H}_{2}$ which can be removed by RWGS (Eq. 2) and hence increases ST selectivity. However, according to the results for single-bed catalytic test, $5 F / N C S$ suffers from a low selectivity which can be attributed to the fast transformation of $\mathrm{Fe}^{3+}$-containing iron oxide phases (red state) to magnetite (black state) when catalyst surface is exposed to ethylbenzene at $873 \mathrm{~K}$ for the first time (Eq. 9). According to the reports published in literature $[1,13,19,25,32]$, well dispersion of active phase on support and redox properties of catalysts play a pivotal role to achieve higher performances, but in this case, we rule out these factors; because both dehydrogenation catalysts have the same structure. As a consequence, the role of oxidation catalyst needs to be highlighted in this work for high selectivity toward ST.

$3 \mathrm{Fe}_{2} \mathrm{O}_{3}+\mathrm{H}_{2} \rightarrow 2 \mathrm{Fe}_{3} \mathrm{O}_{4}+\mathrm{H}_{2} \mathrm{O}$

\subsection{Role of oxidation catalyst}

A glance at Table 2 shows that in the single-bed via only $\mathrm{ODH}$ reaction with $\mathrm{CO}_{2}$, the amount of main side-products, benzene and toluene produced by cracking (Eq. 10) and hydrogenolysis (Eq. 11) $[9,50]$ are enormous compared to the double-bed reactor in the presence of $\mathrm{ODH}$ and oxidation catalysts.

$\mathrm{C}_{6} \mathrm{H}_{5} \mathrm{CH}_{2}-\mathrm{CH}_{3} \rightarrow \mathrm{C}_{6} \mathrm{H}_{6}+\mathrm{C}_{2} \mathrm{H}_{4}$ (cracking)

$\mathrm{C}_{6} \mathrm{H}_{5} \mathrm{CH}_{2}-\mathrm{CH}_{3}+\mathrm{H}_{2} \rightarrow \mathrm{C}_{6} \mathrm{H}_{5} \mathrm{CH}_{3}+\mathrm{CH}_{4}$ (hydrogenolysis)

It is accepted that more acidic catalysts generally support cracking of hydrocarbons expediting generation of more undesired byproducts and coke which subsequently leads to catalyst deactivation $[9,12]$. The effective $\mathrm{ODH}$ with $\mathrm{CO}_{2}$ proceeds on acid-base sites on the catalysts. Wang and coworkers [51] explored from their study that the formation of toluene and benzene are predominately because of the influence of strong acid-base sites on the surface of the catalysts. Strong basic sites can extract the $\beta-\mathrm{H}$ of the adsorbed EB which speeds up the division of side chain $\mathrm{C}-\mathrm{C}$ bond contributing to the formation of toluene (Eq. 9), while the strong acid sites extract $\mathrm{a}-\mathrm{H}$ of $E B$ and accelerate the division of phenyl- $\mathrm{C}$ bond leading to the production of benzene (Eq. 8) (Scheme 2). In the commercial production of ST, following dehydrogenation of $E B$ and production of $\mathrm{H}_{2}$, oxidation catalyst plays a critical role by the subsequent reaction (Eq. 12) [TPC-R\&D]:

$2 \mathrm{H}_{2}+\mathrm{O}_{2} \rightarrow 2 \mathrm{H}_{2} \mathrm{O}$

In our study, this reaction proceeds by $\mathrm{CO}_{2}$ via RWGS (Eq. 2). This reaction clearly demonstrates the further removal of hydrogen from the reaction environment, and consequently results in higher selectivity toward ST compared to the single-bed reactor.

Two major elements of oxidation catalysts are $\mathrm{Sn}$ and $\mathrm{Pt}$ which seems to have an influential role in the performance of the catalyst. Both elements have been extensively investigated in the dehydrogenation of light alkanes $[52,53]$ and now it is proven that alloyed Sn-Pt in the structure of the catalyst increases conversion and selectivity, prevents metal sintering, and suppresses coke formation. Pham et al. [52]. pointed out that the addition of Sn as a promoter helps to modify both the Pt active phase and the support. Since the $\mathrm{Pt}-$ alkene interaction is stronger than 
the $\mathrm{Pt}$-alkane interaction, undesired side reactions such as hydrogenolysis and isomerization can occur; Sn weakens the $\mathrm{Pt}$-alkene interaction without weakening the $\mathrm{Pt}$ - alkane interaction and, therefore, suppresses the side reaction. This is how $\mathrm{Sn}$ is thought to influence the selectivity of the catalyst. With this explanation, the same situation can be envisaged in EB dehydrogenation; Sn softens the Pt-ST bond without softening the Pt-EB interaction. As a result, oxidation catalysts abates unwanted byproducts and enhances the selectivity toward ST.

Further studies over Pt-Sn bimetallic catalysts by Zhu [54] and Late et al. [55]. proved that Pt-Sn bimetallic catalysts are selective and stable in propane dehydrogenation reaction. In addition, there were other reports that $\mathrm{Sn}$ as an additive for $\mathrm{Pt} / \mathrm{Y}-\mathrm{Al}_{2} \mathrm{O}_{3}$ catalysts improved the selectivity and stability of the catalyst in light alkane dehydrogenation reactions. Pham and co-workers stated in their study that the drawback to light paraffin dehydrogenation processes is coking, which deactivates the catalyst $\left(\mathrm{Pt} / \mathrm{Y}-\mathrm{Al}_{2} \mathrm{O}_{3}\right)$ and reduces the selectivity toward olefins. They proved that carbon deposits are not responsible for low catalytic performance, but the transformation of subnanometer $\mathrm{Pt}$ species into larger Pt nanoparticles. The solution by this group was addition of Sn to alumina which remains atomically dispersed and assist to redispersion of Pt on alumina and thereby improves catalytic performance [52]. Moreover, an experiment was conducted for the oxidative dehydrogenation of ethane to compare the catalytic activity of two catalysts, namely $\mathrm{LaMnO}_{3}$ and $0.1 \% \mathrm{Pt} 0.2 \% \mathrm{Sn}$. The results revealed in the temperature interval of $600-900{ }^{\circ} \mathrm{C}$ and at $\mathrm{C}_{2} \mathrm{H}_{6} / \mathrm{O}_{2} / \mathrm{H}_{2}=4 / 1 / 2$ that the two catalysts had roughly the same ethane and oxygen conversion at all temperatures, but the selectivity to ethene was much higher over the Pt-Sn catalyst [56]. Considering these firm reports of well performance of Sn and Pt in the structure of catalysts for light alkanes dehydrogenation, it is quite predictable that in the dehydrogenation as well as oxidation of ethylbenzene, $\mathrm{Pt}$ and $\mathrm{Sn}$ in the structure of oxidation catalyst played a critical role as not only a selective catalyst toward production of ST (>91\%) but also as a stable catalyst at $873 \mathrm{~K}$.

\section{Conclusion}

The primary purpose of this work was to select one of the catalysts (with the lowest performance) that had previously synthesized and tested in oxidative dehydrogenation of ethylbenzene and to improve its catalytic performance. Therefore, 5F/NCS selected and tested in a double-bed reactor with the help of the second catalyst (oxidation catalyst) that was obtained from Tabriz Petrochemical Company. Based on the GC analysis for both catalytic tests, it was confirmed that oxidation catalyst has a profound impact on reducing the amount of sideproducts (benzene and toluene). On the other hand, oxidation catalyst enhanced styrene selectivity by further elimination of hydrogen. Based on previous literature, the presence of Sn and Pt elements in the structure of oxidation catalyst improved selectivity towards styrene. Sn softens the Pt-ST bond without softening the Pt-EB interaction leading to suppression of undesired byproducts and increasing styrene production. Considering the beneficial aspect of dehydrogenation and oxidation catalysts together in a double-bed reactor on one side, and economic factor for commercialization from another side, the further investigations are yet to come.

Acknowledgments The authors express their appreciation to the support from the University of Tabriz, Tabriz Petrochemical Company, and the Iranian Nanotechnology Initiative Council.

\section{Compliance with ethical standards}

Conflict of interest The authors declare that there is no conflict of interest regarding the publication of this paper.

\section{References}

1. Kainthla I, Babu GVR, Bhanushali JT, Rao KSR, Nagaraja BM (2017) Development of stable $\mathrm{MoO}_{3} / \mathrm{TiO}_{2}-\mathrm{Al}_{2} \mathrm{O}_{3}$ catalyst for oxidative dehydrogenation of ethylbenzene to styrene using $\mathrm{CO} 2$ as soft oxidant. J CO2 Util 18:309-317

2. Gurram VRB, Enumula SS, Mutyala S, Pochamoni R, Prasad PS, Burri DR, Kamaraju SRR (2016) The advantage of ceria loading over $\mathrm{V}_{2} \mathrm{O}_{5} / \mathrm{Al}_{2} \mathrm{O}_{3}$ catalyst for vapor phase oxidative dehydrogenation of ethylbenzene to styrene using $\mathrm{CO}_{2}$ as a soft oxidant. Appl Petrochem Res 6:427-437

3. Zhang S-J, Li W-Y, Li X-H (2015) Effect of preparation methods on the catalytic properties of $\mathrm{Fe}_{2} \mathrm{O}_{3} / \mathrm{Al}_{2} \mathrm{O}_{3}-\mathrm{ZrO}_{2}$ for ethylbenzene dehydrogenation. J Fuel Chem Technol 43:437-441

4. Castro AJ, Soares JM, Josue Filho M, Oliveira AC, Campos A, Milet ÉR (2013) Oxidative dehydrogenation of ethylbenzene with $\mathrm{CO}_{2}$ for styrene production over porous iron-based catalysts. Fuel 108:740-748

5. Zhang L, Wu Z, Nelson NC, Sadow AD, Slowing II, Overbury SH (2015) Role of $\mathrm{CO}_{2}$ as a soft oxidant for dehydrogenation of ethylbenzene to styrene over a high-surface-area ceria catalyst. ACS Catal 5:6426-6435

6. Jiang N, Burri A, Park S-E (2016) Ethylbenzene to styrene over $\mathrm{ZrO}_{2}$-based mixed metal oxide catalysts with $\mathrm{CO}_{2}$ as soft oxidant. Chin J Catal 37:3-15

7. Morán C, González E, Sánchez J, Solano R, Carruyo G, Moronta A (2007) Dehydrogenation of ethylbenzene to styrene using Pt Mo, and Pt-Mo catalysts supported on clay nanocomposites. J Colloid Interface Sci 315:164-169

8. Ohishi Y, Kawabata T, Shishido T, Takaki K, Zhang Q, Wang Y, Takehira K (2005) Dehydrogenation of ethylbenzene with $\mathrm{CO}_{2}$ over Cr-MCM-41 catalyst. J Mol Catal A: Chem 230:49-58

9. Reddy BM, Han D-S, Jiang N, Park S-E (2008) Dehydrogenation of ethylbenzene to styrene with carbon dioxide over $\mathrm{ZrO}_{2}$-based composite oxide catalysts. Catal Surv Asia 12:56-69 
10. Sun A, Qin Z, Chen S, Wang J (2004) Ethylbenzene dehydrogenation in the presence of carbon dioxide over alumina supported catalysts. Catal Today 93:273-279

11. Sun A, Qin Z, Wang J (2002) Reaction coupling of ethylbenzene dehydrogenation with water-gas shift. Appl Catal A 234:179-189

12. Chen S, Qin Z, Sun A, Wang J (2006) Theoretical and experimental study on reaction coupling: dehydrogenation of ethylbenzene in the presence of carbon dioxide. J Nat Gas Chem 15:11-20

13. Mukherjee D, Park S-E, Reddy BM (2016) $\mathrm{CO}_{2}$ as a soft oxidant for oxidative dehydrogenation reaction: an eco benign process for industry. J CO2 Util 16:301-312

14. Zhang S, Li X, Jing J, Fan $\mathrm{H}$, Wang Q, Li W (2013) Dehydrogenation of ethylbenzene with $\mathrm{CO}_{2}$ over $\mathrm{V}_{2} \mathrm{O}_{5} / \mathrm{Al}_{2} \mathrm{O}_{3}-\mathrm{ZrO}_{2}$ catalyst. Catal Commun 34:5-10

15. Su D, Maksimova NI, Mestl G, Kuznetsov VL, Keller V, Schlögl R, Keller N (2007) Oxidative dehydrogenation of ethylbenzene to styrene over ultra-dispersed diamond and onion-like carbon. Carbon 45:2145-2151

16. Reddy BM, Lakshmanan $P$, Loridant $S$, Yamada $Y$, Kobayashi $T$, Lopez-Cartes C, Rojas TC, Fernandez A (2006) Structural characterization and oxidative dehydrogenation activity of $\mathrm{V}_{2} \mathrm{O}_{5} / \mathrm{Ce} \mathrm{x}$ $\mathrm{Zr1-x} \mathrm{O}_{2} / \mathrm{SiO}_{2}$ Catalysts. J Phys Chem B 110:9140-9147

17. Rao R, Yang M, Ling Q, Li C, Zhang Q, Yang H, Zhang A (2014) A novel route of enhancing oxidative catalytic activity: hydroxylation of MWCNTs induced by sectional defects. Catal Sci Technol 4:665-671

18. Shiju N, Anilkumar M, Mirajkar S, Gopinath C, Rao B, Satyanarayana C (2005) Oxidative dehydrogenation of ethylbenzene over vanadia-alumina catalysts in the presence of nitrous oxide: structure-activity relationship. J Catal 230:484-492

19. Elfadly A, Badawi A, Yehia F, Mohamed Y, Betiha M, Rabie A (2013) Selective nano alumina supported vanadium oxide catalysts for oxidative dehydrogenation of ethylbenzene to styrene using $\mathrm{CO}_{2}$ as soft oxidant. Egypt J Petrol 22:373-380

20. Chang J-S, Vislovskiy VP (2002) Catalytic dehydrogenation of aromatic hydrocarbon with carbon dioxide as an oxidant, abstracts of papers of the american chemical society, Amer Chemical Soc 1155 16th st, NW, Washington, DC 20036 USA, 2002, pp. U584-U584

21. Kovacevic $M$, Agarwal $S$, Mojet $B L$, van Ommen JG, Lefferts $L$ (2015) The effects of morphology of cerium oxide catalysts for dehydrogenation of ethylbenzene to styrene. Appl Catal A 505:354-364

22. Li C, Sun Y, Zhang A (2015) Binary Ce-Mn oxides confined in carbon nanotubes as efficient catalysts for ethylbenzene dehydrogenation in the presence of carbon dioxide. RSC Advances 5:36394-36403

23. Fan H, Feng J, Li X, Guo Y, Li W, Xie K (2015) Ethylbenzene dehydrogenation to styrene with $\mathrm{CO}_{2}$ over $\mathrm{V}_{2} \mathrm{O}_{5}$ (001): a periodic density functional theory study. Chem Eng Sci 135:403-411

24. Burri A, Jiang N, Ji M, Park S-E, Khalid Y (2013) Oxidative dehydrogenation of ethylbenzene to styrene with $\mathrm{CO}_{2}$ over $\mathrm{V}_{2} \mathrm{O}_{5}-$ $\mathrm{Sb}_{2} \mathrm{O}_{5}-\mathrm{CeO}_{2} / \mathrm{TiO}_{2}-\mathrm{ZrO}_{2}$ catalysts. Top Catal 56:1724-1730

25. Wang T, Qi L, Lu H, Ji M (2017) Flower-like $\mathrm{Al}_{2} \mathrm{O}_{3}$-supported iron oxides as an efficient catalyst for oxidative dehydrogenation of ethlybenzene with $\mathrm{CO}_{2}$. J CO2 Util 17(2017):162-169

26. Qiao Y, Miao C, Yue Y, Xie Z, Yang W, Hua W, Gao ZJM (2009) Vanadium oxide supported on mesoporous MCM-41 as new catalysts for dehydrogenation of ethylbenzene with $\mathrm{CO}_{2}$. Microporous and Mesoporous materials 119:150-157

27. Chunguang $\mathrm{LI}$, Changxi MIAO, Yingying NIE, Yinghong YUE, Songyuan GU, Weimin YANG, Zi GAO (2010) Ethylbenzene dehydrogenation in the presence of $\mathrm{CO} 2$ over MCF-supported vanadium oxide catalysts. Chin J Catal 31:993-998
28. Ye X, Yue Y, Miao C, Xie Z, Hua W, Gao Z (2005) Effect of modifiers on the activity of a $\mathrm{Cr}_{2} \mathrm{O}_{3} / \mathrm{Al}_{2} \mathrm{O}_{3}$ catalyst in the dehydrogenation of ethylbenzene with $\mathrm{CO}$ 2. Green Chem 7(7):524-528

29. Reddy $\mathrm{BM}$, Khan A (2005) Recent advances on $\mathrm{TiO}_{2}-\mathrm{ZrO}_{2}$ mixed oxides as catalysts and catalyst supports. Catal Rev 47:257-296

30. Sadeghi E, Oskoui MS, Khatamian M, Ghassemi AH (2016) Oxidative dehydrogenation of ethylbenzene over ZSM-5 type chromosilicates in the presence of $\mathrm{CO}_{2}$. Mod Res Catal 5:75

31. Khatamian M, Oskoui MS, Sadeghi E (2017) Dehydrogenation of ethylbenzene with carbon dioxide in the presence of chromosilicate-based composites. J Phys Chem C 121:6650-6661

32. Watanabe R, Saito Y, Fukuhara C (2014) Dehydrogenation of ethylbenzene over zirconium-based perovskite-type catalysts of $\mathrm{AZrO}_{3}$ (A: Ca, Sr, Ba). Appl Catal A 482:344-351

33. Khatamian M, Oskoui MS, Darbandi M (2013) Synthesis and characterization of aluminium-free ZSM-5 type chromosilicates in different alkaline systems and investigation of their pore structures. Microporous Mesoporous Mater 182:50-61

34. Ertl G, Knözinger H, Weitkamp J (2008) Preparation of solid catalysts. Wiley, Hoboken

35. Tang C, Sun B, Sun J, Hong X, Deng Y, Gao F, Dong L (2017) Solid state preparation of $\mathrm{NiO}-\mathrm{CeO}_{2}$ catalyst for $\mathrm{NO}$ reduction. Catal Today 281:575-582

36. Rossetti I, Bencini E, Trentini L, Forni L (2005) Study of the deactivation of a commercial catalyst for ethylbenzene dehydrogenation to styrene. Appl Catal A: General 292:118-123

37. Jo MC (2008) Enhancement of catalytic activity of Pt/alumina by a novel pretreatment method for the $\mathrm{CO}$ oxidation for fuel cell applications. J Environ Sci Int 17:1307-1314

38. Ikenaga N-O, Tsuruda T, Senma K, Yamaguchi T, Sakurai Y, Suzuki $\mathrm{T}$ (2000) Dehydrogenation of ethylbenzene with carbon dioxide using activated carbon-supported catalysts. Ind Eng Chem Res 39:1228-1234

39. Ye X, Yue Y, Miao C, Xie Z, Hua W, Gao Z (2005) Effect of modifiers on the activity of $\mathrm{a} \mathrm{Cr}_{2} \mathrm{O}_{3} / \mathrm{Al}_{2} \mathrm{O}_{3}$ catalyst in the dehydrogenation of ethylbenzene with $\mathrm{CO}_{2}$. Green Chem 7:524-528

40. Park J-N, Noh J, Chang J-S, Park S-E (2000) Ethylbenzene to styrene in the presence of carbon dioxide over zirconia. Catal Lett 65:75-78

41. Liu Y-M, Cao Y, Yan S-R, Dai W-L, Fan K-N (2003) Highly effective oxidative dehydrogenation of propane over vanadia supported on mesoporous SBA-15 silica. Catal Lett 88:61-67

42. Van Der Voort $P$, Benjelloun M, Vansant EF (2002) Rationalization of the synthesis of SBA-16: controlling the micro-and mesoporosity. J Phys Chem B 106:9027-9032

43. Kuhrs C, Arita Y, Weiss W, Ranke W, Schlögl R (2000) Understanding heterogeneous catalysis on an atomic scale: a combined surface science and reactivity investigation for the dehydrogenation of ethylbenzene over iron oxide catalysts. Top Catal 14:111-123

44. Catalyst SB (2010) 1. Application of green chemistry in energy production. J Phys Chem A 114:3743

45. Liu B, Chang R, Jiang L, Liu W, Au C (2008) Preparation and high performance of La2O3-V2O5/MCM-41 catalysts for ethylbenzene dehydrogenation in the presence of $\mathrm{CO}_{2}$. J Phys Chem $\mathrm{C}$ 112:15490-15501

46. Saito K, Okuda K, Ikenaga N-O, Miyake T, Suzuki T (2009) Role of lattice oxygen of metal oxides in the dehydrogenation of ethylbenzene under a carbon dioxide atmosphere. J Phys Chem $A$ 114:3845-3854

47. Yan B, Wang L, Wang B, Alam F, Xiao Z, Li J, Jiang T (2019) Constructing a high-efficiency iron-based catalyst for carbon dioxide oxidative dehydrogenation of 1-butene: the role of oxygen mobility and proposed reaction mechanism. Appl Catal A: Gener 572:71-79 
48. Ansari MB, Park S-EJE, Science E (2012) Carbon dioxide utilization as a soft oxidant and promoter in catalysis 5:9419-9437

49. Zhang L, Wu Z, Nelson NC, Sadow AD, Slowing II, Overbury SH (2015) Role of $\mathrm{CO}_{2}$ as a soft oxidant for dehydrogenation of ethylbenzene to styrene over a high-surface-area ceria catalyst. ACS Catal 5(11):6426-6435

50. Sanz SG, McMillan L, McGregor J, Zeitler JA, Al-Yassir N, Al-Khattaf S, Gladden LF (2015) A new perspective on catalytic dehydrogenation of ethylbenzene: the influence of side-reactions on catalytic performance. Catal Sci Technol 5:3782-3797

51. Martinez-Huerta M, Gao X, Tian H, Wachs I, Fierro J, Banares M (2006) Oxidative dehydrogenation of ethane to ethylene over alumina-supported vanadium oxide catalysts: relationship between molecular structures and chemical reactivity. Catal Today 118:279-287

52. Pham HN, Sattler JJ, Weckhuysen BM, Datye AK (2016) Role of Sn in the regeneration of $\mathrm{Pt} / \mathrm{Y}-\mathrm{Al} 2 \mathrm{O} 3$ light alkane dehydrogenation catalysts. ACS Catal 6:2257-2264
53. Kaneko S, Arakawa T, Ohshima M-A, Kurokawa H, Miura H (2009) Dehydrogenation of propane combined with selective hydrogen combustion over Pt-Sn bimetallic catalysts. Appl Catal A 356:80-87

54. Zhu H, Anjum DH, Wang Q, Abou-Hamad E, Emsley L, Dong $\mathrm{H}$, Laveille P, Li L, Samal AK, Basset J-M (2014) Sn surface-enriched Pt-Sn bimetallic nanoparticles as a selective and stable catalyst for propane dehydrogenation. J Catal 320:52-62

55. Låte L, Thelin W, Blekkan E (2004) Selective combustion of hydrogen in the presence of hydrocarbons: part 2. Metal oxide based catalysts. Appl Catal A: Gener 262:63-68

56. Håkonsen S, Walmsley J, Holmen A (2010) Ethene production by oxidative dehydrogenation of ethane at short contact times over Pt-Sn coated monoliths. Appl Catal A 378:1-10

Publisher's Note Springer Nature remains neutral with regard to jurisdictional claims in published maps and institutional affiliations. 